\title{
Ultrasound-guided biodegradable subacromial spacer implantation in a patient with massive irreparable rotator cuff tears
}

\author{
Tomasz Poboży ${ }^{1}$, Maciej Kielar ${ }^{2,3}$, Jakub Miąskiewicz ${ }^{4}$ \\ ${ }^{1}$ Department of Orthopedic Surgery, Surgery Clinic, Medicover Hospital, Warsaw, Poland \\ 2Department of Oncology and Nursing Oncology, Institute of Nursing and Obstetrics, Faculty of Medicine and Health Science, \\ Jan Kochanowski University, Kielce, Poland \\ ${ }^{3}$ First Chair and Clinic of General and Vascular Surgery, Second Faculty of Medicine with the English Division, Medical University \\ of Warsaw, Warsaw, Poland \\ ${ }^{4}$ National Institute of Geriatrics, Rheumatology and Rehabilitation, Warsaw, Poland
}

Videosurgery Miniinv 2019; 14 (1): 145-148 DOI: https://doi.org/10.5114/wiitm.2018.77555

\begin{abstract}
The aim of this manuscript is to present a modification of the current arthroscopic implantation technique of a biodegradable subacromial spacer. This modified ultrasound-guided technique was intended to maximally reduce the invasiveness of the procedure. The ultrasound technique was used to measure the subacromial space for an optimal fit and to verify subacromial spacer placement in the sagittal and frontal planes. This finding is of particular importance for patients with contraindications to general or regional anesthesia. The follow-up (5 months) of subacromial spacer implantation using ultrasound in a patient with an irreparable rotator cuff tear showed correct spacer placement.
\end{abstract}

Key words: ultrasonography, glenohumeral joint, rotator cuff tears, biodegradable subacromial spacer, ultrasound-guided implantation.

\section{Introduction}

Biodegradable subacromial spacer implantation (Photo 1) offers a chance for a normal life to patients with massive, irreparable rotator cuff tears [1-3]. This relatively low invasive method has been the established standard of treatment [4-8] and can be accomplished with ultrasound guidance and local anesthesia.

The use of trapezoidal ultrasound imaging or the use of a convex probe enables the operator not only to examine the area underneath the acromion and visualize the upper part of the glenoid cavity along with the corresponding part of the glenoid rim but also to visualize any implants, needles, and other instruments inserted into this region during the pro- cedure [9-11]. Notably, all this is achieved with nothing more than local anesthesia with suprascapular nerve block.

\section{Case report}

The female patient was admitted to the hospital because of a massive rotator cuff tear in her right shoulder, most likely sustained several months previously. The tear was confirmed ultrasonographically. The patient had medical contraindications for general anesthesia and long-lasting surgical procedures. At the time of the procedure (2015 Jan), the patient was 73 years old (height $158 \mathrm{~cm}$, weight $56 \mathrm{~kg})$. The condition of her glenohumeral joint on physical examination preceding the procedure was

\section{Address for correspondence}

Tomasz Poboży MD, PhD, Department of Orthopedic Surgery, Surgery Clinic, Medicover Hospital, Al. Rzeczypospolitej 5, 02-972 Warsaw,

Poland, phone: +48 600980 648, e-mail: pobozytomasz@gmail.com 


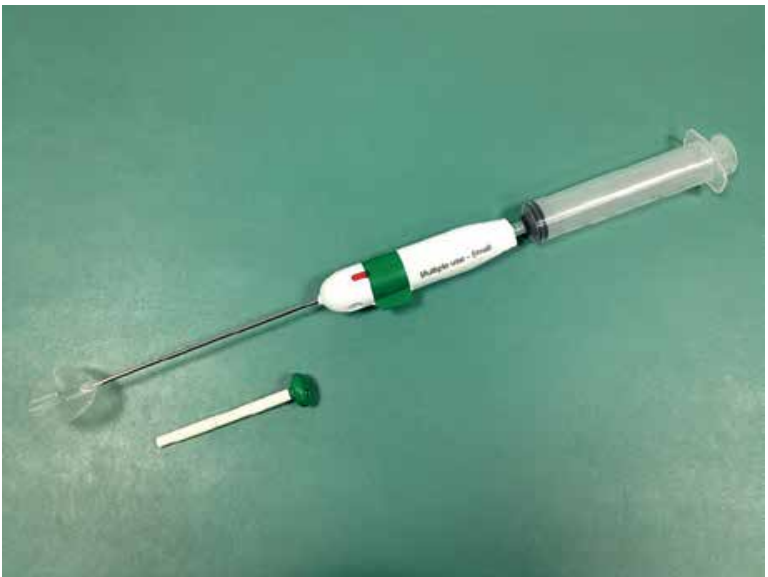

Photo 1. OrthoSpace InSpace Balloon System

as follows: abduction up to approximately $60^{\circ}$, joint crepitations, decrease in muscle strength (3/5), positive Hawkins and Neer subacromial impingement signs, and radiographic evidence of a significantly narrowed subacromial space. The patient received a subacromial spacer (balloon), size $M$ (middle), under ultrasound control with confirmation under fluoroscopy and arthroscopy.

The patient stayed in the hospital for a total of 3 days. Immediately after the procedure, we ob-

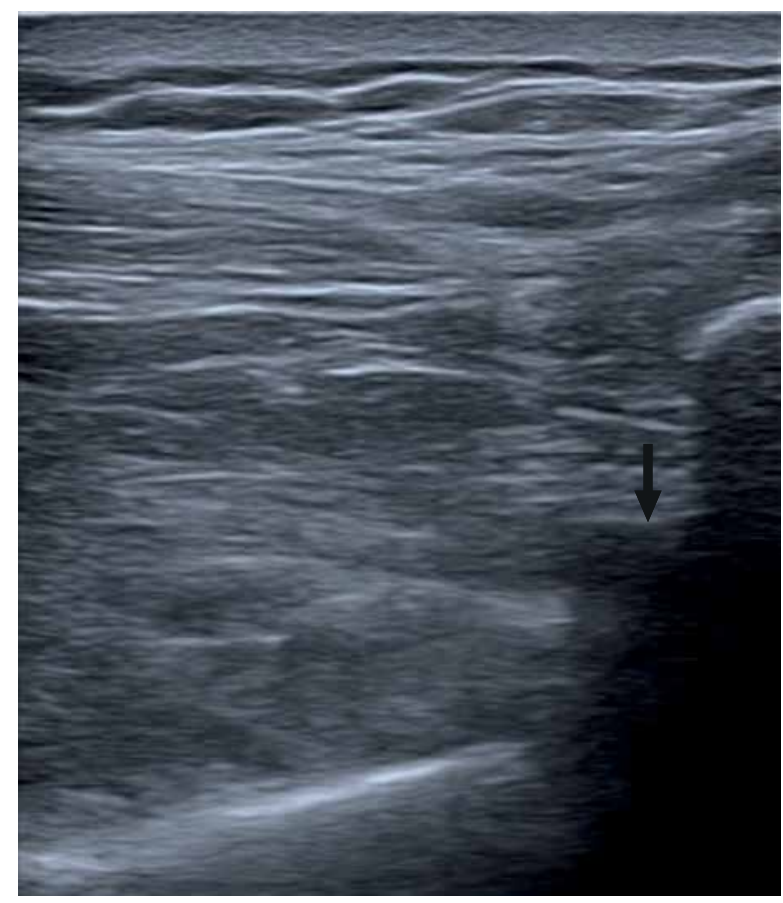

Photo 2. Cannula located approx. $10 \mathrm{~mm}$ medially to the superior rim of the glenoid cavity (arrow) served a significant improvement in the range of motion and pain severity. Two days after the procedure, the limb was no longer immobilized, allowing for active movements.

We assessed the length (size) of the balloon for implantation by measuring the distance from the lateral border of the acromion to the point located $10 \mathrm{~mm}$ medially to the superior rim of the glenoid cavity. This assessment was conducted with a long needle for injections $(1.00 \times 120 \mathrm{~mm}$ - TSK Laboratory, Japan). Subsequently, the subacromial bursa was anesthetized, a needle was inserted from the side into the site located 10 to $15 \mathrm{~mm}$ medially to the superior rim of the glenoid cavity, and the tip of the needle was positioned in such a way as to be visible on the ultrasound monitor at the site where the balloon-containing introducer cannula would eventually be placed (Photo 2). Additionally, we palpated (and visualized with ultrasound) the lateral border of the acromion in order to rest the tip of another same-length needle against this osseous marker. Subsequently, based on the difference in the lengths of the parts of the needles remaining outside, we estimated the size of the balloon to be deployed in the subacromial space.

After determining the balloon size, we inserted a balloon-containing introducer under ultrasound guidance so that its tip was located above and approximately $10 \mathrm{~mm}$ medial to the superior rim of the glenoid cavity.

After inserting the balloon introducer into the desired position in the subacromial space, the introducer was withdrawn and the balloon was inflated with

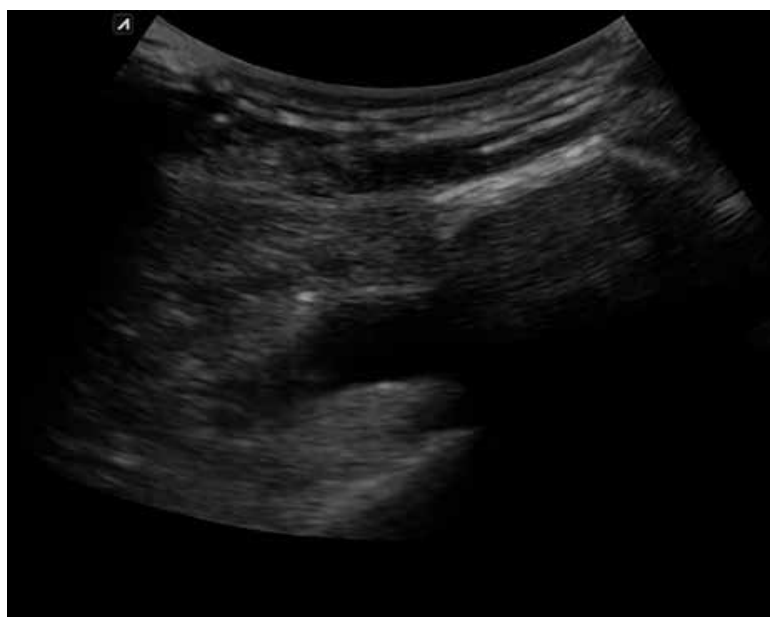

Photo 3. Spacer inflated to the maximum volume suitable for the given balloon size 
saline solution $(0.9 \% \mathrm{NaCl})$ to the volume suitable for the given balloon size (Photo 3). Subsequently, an appropriate volume of saline was withdrawn, according to the requirements of the given procedure, to ensure the full range of motion (Photo 4). Then, the appropriately inflated balloon was detached from the inflation line and left in the subacromial space [4-7, 12].

We conducted the procedure with local anesthesia, with the patient in the beach-chair position.

Approximately $3 \mathrm{ml}$ of $1 \%$ lignocaine was used to anesthetize the skin and deeper tissues for lateral port placement (this port was later used for introducing the catheter with the spacer). Subsequently, a needle was inserted under ultrasound guidance into the subacromial space above the superior part of the glenoid rim. The anesthetic $(15 \mathrm{ml}$ of $0.5 \%$ Marcaine solution $+5 \mathrm{ml}$ of $2 \%$ lignocaine) was injected as the needle was slowly withdrawn. Additionally, the suprascapular nerve in the area of the suprascapular notch was anesthetized (also under ultrasound guidance) with $10 \mathrm{ml}$ of $0.25 \%$ Marcaine.

We also assessed the outcome of the procedure with the Constant score $[6,8,11,13-15]$. The patient underwent ultrasound examinations in the postoperative period. Less than half a year after the procedure, the patient exhibited the full range of motion in the shoulder and a high level of satisfaction with the outcome of the procedure (Constant score: pain 0 vs. 15; activity 4 vs. 20; range of motion 12 vs. 34 ; strength 0 vs. 12 ; total 16 vs. 81 ). The Constant score questionnaire was used 2 weeks prior to and 2 months after the procedure. The implanted balloon underwent partial degradation within the 5-month follow-up, with only a slight posterior displacement. However, what was interesting in this case was the fact that a relatively thick (approximately $3.4 \mathrm{~mm}$ ) layer of scar tissue formed at the place that was occupied by the implanted balloon at the site of the rotator cuff tear. This scar tissue continued to isolate the humeral head from the acromion despite the fact that the partially degraded balloon had lost its properties, as visualized via an ultrasound examination (Photo 5).

\section{Discussion}

Earlier reports on the use of subacromial spacers as an innovative technique in arthroscopic surgery in patients with massive irreparable full-width ro-

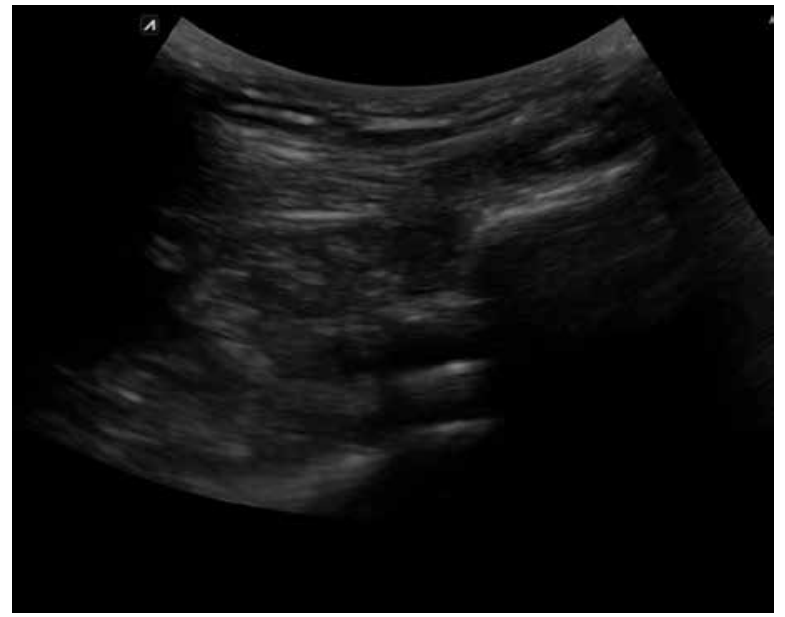

Photo 4. Spacer after an appropriate volume of saline was withdrawn (final view after procedure)

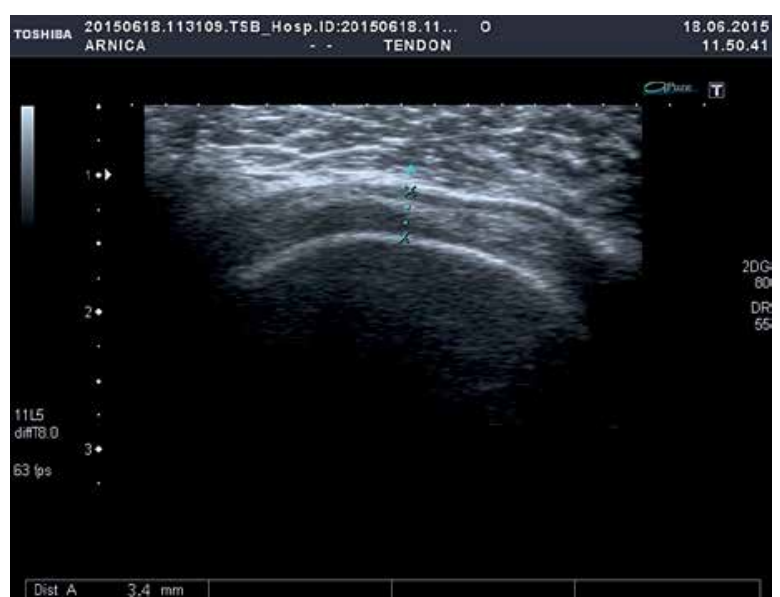

Photo 5. Ultrasound image of the patient's shoulder obtained 5 months after the procedure

tator cuff tears appeared in 2012 [4-8, 12, 16]. The authors of those, and subsequent, reports claimed that implanting a biodegradable balloon into the subacromial space should reduce friction and improve joint mobility by lowering the humeral head. However, it is still too early to assess long-term outcomes of this treatment approach, though the findings of a 3- and 5-year follow-up in 20 patients presented by Senekovic et al. $[5,8]$ are promising. The implanted spacer undergoes complete degradation within 12 months. Although it seems obvious that an inflated spacer isolates the humeral head from the acromion, the continual pain-free shoulder motion and maintained good shoulder function in the period beyond 12 months, i.e., when the spacer had already undergone disintegration [17], are still not 
entirely understood. Our findings, namely, scar tissue formation in the subacromial space, may help explain this conundrum.

\section{Conclusions}

As far as we know, this is the first report on the use of ultrasound as the main imaging technique to ensure visual guidance during all steps of subacromial spacer implantation with local anesthesia in a patient with massive irreparable rotator cuff tears. At the end of the follow-up period (5 months), the patient showed favorable signs in the form of a layer of scar tissue that isolated the humeral head from the acromion, resulting in significantly increased joint mobility, pain alleviation, and improved quality of life.

The procedure presented here is not a novel technique. It is a modification of an established approach and should be treated as a complement to the techniques already used for subacromial spacer implantation. This treatment approach can be recommended and may be warranted in certain clinical situations; however, further studies are needed.

\section{Conflict of interest}

The authors declare no conflict of interest.

\section{References}

1. Delaney RA, Lin A, Warner JJ. Nonarthroplasty options for the management of massive and irreparable rotator cuff tears. Clin Sports Med 2012; 31: 727-48.

2. Bedi A, Dines J, Warren RF, Dines DM. Massive tears of the rotator cuff. J Bone Joint Surg Am 2010; 92: 1894-908.

3. Lubiatowski P, Wojtaszek M, Ogrodowicz P, et al. Przeniesienie mięśnia najszerszego grzbietu w nienaprawialnych uszkodzeniach pierścienia rotatorów. Chirurgia Narządów Ruchu i Ortopedia Polska 2008; 73: 316-21.

4. Savarese E, Romeo R. New solution for massive, irreparable rotator cuff tears: the subacromial "biodegradable spacer". Arthrosc Tech 2012; 1: e69-74.

5. Senekovic V, Poberaj B, Kovacic L, et al. Prospective clinical study of a novel biodegradable subacromial spacer in treatment of massive irreparable rotator cuff tears. Eur J Orthop Surg Traumatol 2013; 23: 311-6.

6. Gervasi E, Cautero E, Dekel A. Fluoroscopy-guided implantation of subacromial "Biodegradable Spacer" using local anesthesia in patients with irreparable rotator cuff tear. Arthrosc Tech 2014; 3: 455-8.

7. Szöllösy G, Rosso C, Fogerty S, et al. Subacromial spacer placement for protection of rotator cuff repair. Arthrosc Tech 2014; 3: 605-9.
8. Senekovic V, Poberaj B, Kovacic L, et al. The biodegradable spacer as a novel treatment modality for massive rotator cuff tears: a prospective study with 5-year follow-up. Arch Orthop Trauma Surg 2017; 137: 95-103.

9. Poboży T, Kielar M. A review of ultrasonographic methods for the assessment of the anterior cruciate ligament in patients with knee instability - diagnostics using a posterior approach. J Ultrason 2016; 16: 288-95.

10. Micheroli R, Kyburz D, Ciurea A, et al. Correlation of findings in clinical and high resolution ultrasonography examinations of the painful shoulder. J Ultrason 2015; 15: 29-44.

11. Barth J, Fotiadis E, Barthelemy R, et al. Ultrasonic evaluation of the repair integrity can predict functional outcomes after arthroscopic double-row rotator cuff repair. Knee Surg Sports Traumatol Artrosc 2015; 23: 376-85.

12. Gervasi E, Maman E, Dekel A, Cautero E. Fluoroscopy-guided biodegradable spacer implantation using local anesthesia: safety and efficacy study in patients with massive rotator cuff tears. Musculoskelet Surg 2016; 100 (Suppl 1): 19-24.

13. Goutallier D, Postel JM, Gleyze P, et al. Influence of cuff muscle fatty degeneration on anatomic and functional outcomes after simple suture of full-thickness tears. J Shoulder Elbow Surg 2003; 12: 550-4.

14. Constant CR, Murley AH. A clinical method of functional assessment of the shoulder. Clin Orthop Relat Res 1987; 214: 160-64.

15. Kwapisz A, Synder M, Domżalski M. Odległa ocena funkcji stawu ramiennego po zachowawczym leczeniu przemieszczonych złamań obojczyka. Kwart Ortop 2012; 3: 390-7.

16. Bozkurt M, Akkaya M, Gursoy S, Isik C. Augmented fixation with biodegradable subacromial spacer after repair of massive rotator cuff tear. Arthrosc Tech 2015; 4: 471-4.

17. Deranlot J, Herisson O, Nourissat G, et al. Arthroscopic subacromial spacer implantation in patients with massive irreparable rotator cuff tears: clinical and radiographic results of 39 retrospectives cases. Arthroscopy 2017; 33: 1639-44.

Received: 14.02.2018, accepted: 15.06.2018. 